\title{
Estudo da eficácia da videolaparoscopia na avaliação de pacientes com endometriose pélvica
}

Autor: Dilermando Pereira de Almeida Filho

Orientadora: Vivian Ferreira do Amaral

Dissertação apresentada para a obtenção do título de Mestre ao Programa de Pós-graduação em Ciências da Saúde da Pontifícia Universidade Católica do Paraná - PUCPR, em 12 de maio de 2006.

A endometriose pélvica é uma doença complexa, de alto impacto sobre a qualidade de vida das mulheres e sobre os sistemas nacionais de saúde pública. A videolaparoscopia, nos últimos 30 anos, tornou-se indispensável para o diagnóstico preciso da endometriose. O objetivo geral deste estudo foi avaliar as manifestações clínicas da endometriose pélvica, os locais de acometimento e estadiamento, correlacionando os achados macroscópicos com a comprovação histológica. Os objetivos específicos foram: avaliar a eficácia da videolaparoscopia isolada como ferramenta diagnóstica da endometriose e observar a tendência à lateralidade da endometriose pélvica na população de estudo. Foram analisadas 976 pacientes submetidas a videolaparoscopia no Serviço de Ginecologia do Hospital Santa Cruz, Curitiba, PR. Destas, $468(47,9 \%)$ apresentaram ao exame, quadro clínico e videolaparoscópico compativeis com endometriose, e, 337 (34.5\% do total) tiveram o diagnóstico confirmado pelo estudo histopatológico. De 508 pacientes submetidas à videolaparoscopia por outras causas, o estudo histopatológico determinou, além da doença principal, endometriose pélvica em 8 pacientes, totalizando 345 mulheres $(35,3 \%)$ com a doença confirmada na amostra populacional estudada. Entre as pacientes com endometriose confirmada, a dor pélvica foi verificada em $98 \%$ dos casos e em todos os estádios da doença. Não foi observada associação estatisticamente significativa entre diagnóstico confirmado de endometriose e (I) dor pélvica $(p=0,65)$; (II) infertilidade primária $(p=0,29)$, e (III) infertilidade secundária $(p=0,91)$. Evidência positiva para associação foi detectada entre diagnóstico de endometriose e dismenorréia $(\mathrm{p}=0,03)$. O experimento resultou em valores de sensibilidade de $97,88 \%$, especificidade de $79,23 \%$, valor preditivo positivo de $72 \%$, valor preditivo negativo de $98,42 \%$ e acurácia de $85,75 \%$. Estes resultados sugerem uma eficácia limitada para a videolaparoscopia isolada, que deve estar sempre associada ao exame histopatológico na investigação da endometriose.

PALAVRAS-CHAVE: Endometriose pélvica; Laparoscopia; Endometriose; Infertilidade

\section{0 efeito da deambulação na fase ativa do trabalho de parto}

Resumo de Tese

The effect of walking on the active phase of labor

Autora: Fabiana Villela Mamede

Orientadora: Profa. Dra. Ana Maria de Almeida

Trabalho desenvolvido no Centro de Parto Normal do Amparo Maternal de São Paulo

Tese apresentada à Escola de Enfermagem de Ribeirão Preto da Universidade de São Paulo, para obtenção do Título de Doutor pelo Programa de Pós-Graduação, nível Doutorado em Enfermagem em Saúde Pública, (inserido na linha de pesquisa Assistência à Saúde da Mulher no Ciclo Vital), em 1 de setembro de 2005.

Resumo: O objetivo deste estudo foi analisar os efeitos da deambulação na fase ativa do trabalho de parto em primíparas, com 37 semanas ou mais de idade gestacional, no início da fase ativa do trabalho de parto. Foi um estudo analítico de intervenção do tipo quase experimental, realizado no Centro de Parto Normal do Amparo Maternal de São Paulo, no período de julho a agosto de 2004. Fizeram parte do estudo 80 parturientes, admitidas em trabalho de parto espontâneo, com feto único e vivo em apresentação cefálica, membranas integras e presença de líquido amniótico claro. As parturientes realizavam a avaliação da dor através da Escala Visual Numérica de Dor. Após esta resposta, era colocado o podômetro (instrumento para medir distância percorrida, em metros) e a parturiente era estimulada a deambular. Os escores de dor bem como o trajeto deambulado fora tomados e registrados a cada hora até o final da fase ativa do trabalho de parto. Os dados obstétricos foram tomados conforme a evolução do trabalho de parto. O estudo evidenciou que as parturientes percorreram uma distância média de 1624 metros, $63,1 \%$ da fase ativa do trabalho de parto e em um tempo médio de 5 horas. Verificou-se que a quantidade deambulada durante as três primeiras horas da fase ativa está associada a um encurtamento do trabalho de parto, sendo que a cada 100 metros percorridos ocorreu uma diminuição de 22 minutos na primeira hora, 10 minutos na segunda hora e 6 minutos na terceira hora. Os dados apontam que a indicação do uso de ocitócito e ruptura da bolsa amniótica não influenciaram na duração da fase ativa do trabalho de parto. Quanto aos escores de dor, verificou-se que a pontuação dos mesmos aumentou à medida que a dilatação cervical avançava. Foi encontrada uma correlação positiva apenas aos $5 \mathrm{~cm}$ de dilatação, ou seja, quanto maior os trajetos percorridos maiores foram os escores de dor pontuados pelas parturientes.

PALAVRAS-CHAVE: Parto; Trabalho de parto; Dor; Deambulação; Trabalho de parto (fase ativa) 